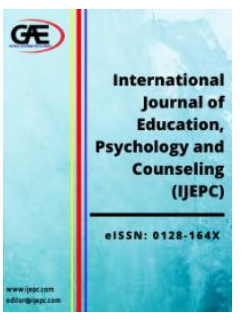

\author{
INTERNATIONAL JOURNAL OF \\ EDUCATION, PSYCHOLOGY \\ AND COUNSELLING \\ (IJEPC) \\ www.ijepc.com
}

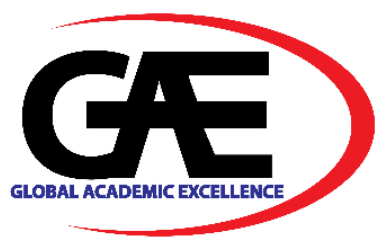

\title{
ENHANCING ACADEMIC PERFORMANCE \& SOCIAL EMOTIONAL LEARNING (SEL) WITH THE BRAIN ENHANCEMENT PROGRAM ("BTE")
}

\author{
Chirag Bhikamchand Jain ${ }^{1 *}$, Darshana Chirag Jain ${ }^{2}$ \\ 1 Department of Research, Mindful Gurukul University, India \\ Email: chiragjain@mindfulgurukul.com \\ 2 Department of Mindfulness, Mindful Gurukul University, India \\ Email: darshana@mindfulgurukul.com \\ Corresponding Author
}

\section{Article Info:}

Article history:

Received date: 04.07.2021

Revised date: 27.07.2021

Accepted date: 01.08.2021

Published date: 05.09.2021

To cite this document:

Jain, C. B., \& Jain, D. C. (2021).

Enhancing Academic Performance \& Social Emotional Learning (SEL) With The Brain Enhancement Program ("BTE"). International Journal of Education, Psychology and Counseling, 4 (42), 111-132.

DOI: $10.35631 /$ IJEPC.642010.

This work is licensed under $\mathrm{CC}$ BY 4.0 (c)

\begin{abstract}
:
Social Emotional Learning is a core competency in the coming future as mankind has created and invented a gadget, device or an app for almost most of technical and knowledge-based needs. Especially during the pandemic, the need for SEL programs becomes a necessity. The important process then remains to create individuals with sensitivity to navigate in such endowed systems, without feeling too powerful or at the polar end without feeling disconnected. It is undeniable society at large will be living with this sense of having the world at their fingertips! It is exactly because of this reason that it is necessary to be socially emotionally adjusted to co-exist with many such equally gifted or talented people around oneself. At the same time the children are exposed to the fast-paced world and ever demanding need to excel and perform better academically. The Brain Training Enhancement Program ("BTE") is a scientifically designed well researched program using Neurofeedback to improve the brain ability of students in competitive exams. The A pre- and post-test quasi-experimental design was used to test the impact of a 10-week, online-based social and emotional learning (SEL) intervention, Brain Training Enhancement Program ("BTE"), on the academic performance and social and emotional competence of $12^{\text {th }}$ grade students $(N=82)$ in two classrooms in one school. Academic performance was assessed by report card grades done in the immediate past and immediately post intervention. Social and emotional competence was assessed with Psychometric Analysis and QEEG Measurements. Students in classrooms integrating BTE program had higher year-end grades and higher scores of social and emotional competences (e.g., Engagement, Self-Regulation, and Focus) compared to students in the comparison group. This study provides preliminary empirical evidence that SEL programs like BTE improve important student outcomes.
\end{abstract}


Keywords:

Social And Emotional Learning, Emotional Literacy, Emotional Intelligence Education School-Based Intervention, BTE Program, Academic Grades, Brain Training

\section{Introduction}

"I have often observed, with deep regret, that educability of the intelligence is often prevented. The idea of 'once a dunce, always a dunce' seems to go unchallenged by teachers; these teachers lose interest in students who lack intelligence - they show them neither sympathy nor respect, using such unmeasured language in front of the children that they say things like: "This boy will never be good for anything ... he has no gifting, no intelligence". Many times I have heard such careless words. They are repeated daily in primary schools and also in secondary. I remember during my Baccalaureate exam in Letters, Martha the examiner became indignant over one of my answers (I confused the name of a Greek philosophy with one of the character names from La Bruyère). She declared that I would never have the philosophic spirit. "Never!" What a daring word! Some recent philosophers seem to give moral support to such deplorable verdicts, affirming that an individual's intelligence is a fixed quantity, a quantity that cannot increase. We must protest and counteract this brutal pessimism; let us demonstrate that it has no basis whatsoever." (Alfred Binet, 1909).

A century after these thoughts from Alfred Binet (1909), we continue to be concerned about how to get pupils to improve both their intellectual ability and their academic performance. Thus, it is ironic that today Binet is more famous in our university classrooms for his invention of the concept Intelligence Quotient (IQ) than for his almost desperate attempts to design educational programs that, as we would say today, integrate children with intellectual and learning disabilities.

However, if we analyse the Binet quote from a more psychological point of view, we find that the anecdote he recounts - his teacher Martha's behaviour during his Baccalaureate exam - is a very negative emotional memory. Binet politely refers to the daring word, "Never!" (we prefer to call it reckless), which still rings in his ears when he writes Modern Ideas about Children at the end of his life (he died in 1911). Fortunately, young Alfred did not listen to the reckless, discouraging words of his teacher, and years later became a full professor at La Sorbonne, and an original, very influential thinker. Today, Alfred Binet is considered one of the fathers of modern psychology, with more than 115,000 entries in Google.

Unfortunately, not all children who hear such "daring" affirmations, for example, about their intellectual or physical abilities, whether at school or at home, are able to emotionally rise above their effects. The necessary emotional and social competencies for coping adequately with negative, destructive emotions generated in such a competitive context as school have not been explicitly taught in our culture. Why not? Because in our society, and specifically at school, up until the end of the 20th century, intellectual and academic aspects of students have been given priority, under the conviction that their emotional and social aspects belong to the private sphere, where each individual is responsible for his or her own personal development (Evans, 2002; Fernández-Berrocal \& Ramos, 2002). 


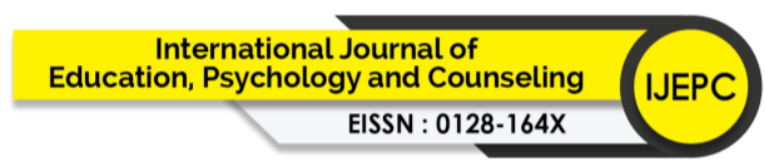

Volume 6 Issue 42 (September 2021) PP. 111-132

DOI 10.35631/IJEPC.642010

The 21 st century has brought a new view of the more diverse reality of human functioning, and we are slowing but surely becoming aware of the need for families to address the education of emotional and social aspects, and for schools and society to explicitly do so as well. Gilles Lipovetsky points out that postmodern societies in the first world want not only to be wealthy, opulent and among the top 25 countries in GDP (Gross Domestic Project), but, since the end of the 20th century, they are desirous of something more. Ultramodern, 21 st century societies, as Lipovetsky calls them, not only desire material consumption, but they also are looking for a new values hierarchy and a new way to relate to objects and time, to ourselves and to other persons, in order to find individual happiness (Lipovetsky, 2006). Ultramodern societies seek for their citizens' satisfaction in life, because it is a very painful paradox for the individual to live in an opulent society which covers one's physical and material needs but does not make one happy.

\section{Literature Review}

Over the last two decades, numerous programs have been developed to promote social and emotional learning (SEL) among youth (Elias et al., 1997, Greenberg et al., 2003). SEL programs are designed to complement existing school curricula by teaching the social and emotional skills that contribute to better social and emotional adjustment and higher academic achievement (Salovey and Sluyter, 1997, Zins et al., 2004).

A recent meta-analysis of 207 studies examining the effects of SEL programs revealed that students enrolled in such programs perform significantly better in school and on standardized tests compared to non-participating students (Durlak, Weissberg, Dymnicki, Taylor, \& Schellinger, in press). The average effect size obtained for SEL programming on academic performance, Hedges' $\mathrm{g}=0.22$, is comparable to those obtained for other educational interventions.

In an era of academic accountability, receptivity toward integrating SEL programming into the curriculum is dependent upon empirical evidence demonstrating improvements in academic performance and social and emotional competence. The study presented here tests the effectiveness of an online-based SEL program in enhancing student outcomes.

The cognitive (thoughts), physiological (bodily feeling), and behavioural (action) changes that accompany emotional experiences are adaptive when the information they provide is attended to, interpreted, understood, used, and managed effectively (Denham, 1998, Lazarus, 1991, Mayer and Salovey, 1997, Saarni, 1999). BTE is grounded in emotional intelligence theory, which suggests that the ability to process emotional information can enhance cognitive activities (i.e., thinking, decision-making, and remembering), promote well-being, and facilitate social functioning (Mayer and Salovey, 1997, Salovey and Mayer, 1990).

The Brain Enhancement Program ("BTE”), ("BTE";Dr.Chirag Jain, 2021) is one component of a comprehensive approach to SEL, called The BTE Approach, that includes Academic and emotional development for school and college students especially enrolled in exit exams like high school or professional education. Anchored in laws of neuro plasticity (Dr. Chirag Jain, 2016) and research on emotional development (e.g., Denham, 1998) and emotional competence (e.g., Saarni, 1999), BTE was designed to be integrated into existing school curricula and to aid students in achieving national educational goals such as those articulated by the No Child 


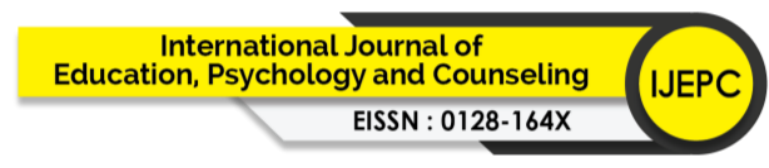

Volume 6 Issue 42 (September 2021) PP. 111-132

DOI 10.35631/IJEPC.642010

Left Behind Act (NCLB, 2001). BTE uses a skill-based approach to foster social, emotional, and academic competence.

\section{The BTE Program}

The BTE adheres strictly to the principle of $4 \mathrm{R}$ namely Realization, Raising an anchor, Rewiring and Redefining.

The program teaches children how to realize emotions in oneself and in other people, understand the causes and consequences of a wide range of emotions, raising an anchor by labelling the emotions and mindfulness activities, rewiring the neural pathway by expressing the emotions in appropriate ways, and finally redefining the neurals by regulating the emotions effectively (the "BTE" skills).

BTE helps students to learn these skills by integrating the activities and developing them into permanent habits and opportunities to practice using them into regular classroom instruction. The premise is that teaching and providing opportunities to develop the BTE skills is necessary to build relationships, promote healthy living, prevent problematic behaviour, and increase academic achievement (Brackett \& Rivers, forthcoming).

Indeed, research shows that emotions are pervasive in daily life and affect how children and adults think, learn, feel, and act (Damasio, 1994). Observe any classroom for any length of time or a child preparing for any major competitive exams - it is obvious that students' daily experiences are saturated with emotions such as frustration, loneliness, enjoyment, and interest (as are the experiences of their teachers, principals, and family members).

We use the term "emotional literacy" to refer to the acquisition and development of the BTE skills, just as "literacy" refers to the acquisition and development of reading and writing skills.

BTE is based on the premise that students will be more effective when they become emotionally literate, i.e., they develop their BTE skills, appreciate the value of these skills, and use these skills to problem-solve and interact effectively with others. The intervention under evaluation here helps students acquire and develop the interrelated but distinct skills of recognizing, understanding, labeling, expressing, and regulating emotions and teaches these skills directly, just as reading programs teach the distinct skills that form the foundation for reading (phonemic awareness, sounds, symbols, etc.).

The BTE is a 10-week program, structured intervention designed to promote social, emotional, and academic learning with units and lessons centered on developing emotional intelligence and permanent habits to have a scientific approach to the exam preparation and studying for any competitive exams. BTE aims simultaneously to enhance the social and emotional skills of adolescents and create an optimal learning environment that promotes academic, social, and personal effectiveness. Like other programs that effectively foster SEL, BTE uses a synergistic approach to education that incorporates the learner, the learning process, and the learning environment (McCombs, 2004).

BTE adheres to best practice guidelines set forth by the Collaborative for Academic, Social, and Emotional Learning (http://www.CASEL.org). These guidelines include linking socialemotional instruction to standard curricula without taking time and focus from other academic 


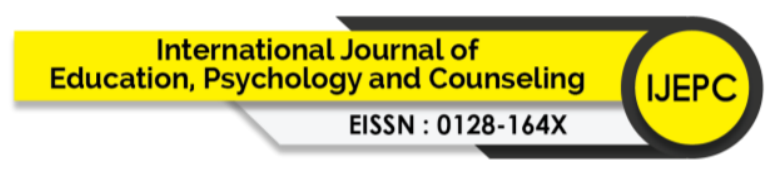

Volume 6 Issue 42 (September 2021) PP. 111-132

DOI 10.35631/IJEPC.642010

areas; providing differentiated instructional procedures; involving parents; training and supporting teachers and staff; and demonstrating program quality through empirical evidence (Elias, 2006, Elias et al., 1997, Zins et al., 2004).

BTE is grounded in theory, provides developmentally appropriate instruction across time, offers classroom instruction that engenders positive student interactions, attempts to create a caring and engaging learning environment, and involves active participation from students, parents, and the school community in the planning, learning, and evaluation process.

In sum, BTE leverages existing curricula and provides lessons designed to enhance outcomes related to both academics (e.g., reading, writing, memorizing and creativity) and social and emotional competence (e.g., healthy relationships, better decision-making, and prosocial behaviour). It is designed to last across the academic year with activities monitored every week for a period of seventy days.

This study used a quasi-experimental design with a pre- and post-test to evaluate the extent to which integrating BTE into existing curricula increases academic grades and social and emotional competence over the course of seventy days (about 2 and half months). We tested two hypotheses. First, because BTE is designed to teach skills related to emotion management and developing habits that will help them in improving their persistence and breaking study fatigue, we predicted that students in BTE classrooms would have greater gains in both EEG readings predicting improved focus, engagement and other social and emotional competencies compared to students in classrooms not using BTE (comparison classrooms) (Hypothesis 1).

BTE infuses certain habits and discipline directly by making them solve short activities and create healthy competition and teaches children to be more self-aware and self-managed, thus we expected to see gains in grades assessing performance in regular class assessments (Hypothesis 2).

We also looked at scores related to emotional stability and work habits and social development by Psychometric Analysis pre and post the program. We predicted that students in BTE classrooms would demonstrate greater gains in grades in these areas (Hypothesis 3 ).

Based on a meta-analysis of SEL programs (Durlak et al., in press), we expected a moderate effect size for social and emotional competencies and small effect sizes for the other outcomes.

\section{Method}

\section{Participants}

A secondary school aided by charity in Bangalore, India volunteered after taking due permission from the students and their parents to participate in the online BTE program evaluation. The ethnic and racial background of students in these schools was diverse with both girls and boys selected as participants. All students in these schools were eligible for free lunch $(\tilde{\mathrm{n}} 7 \%)$, an indicator of socioeconomic status.

Students of Class 12th were divided randomly, based on the gender, Academic results, to teach BTE for 30 students online for a period of 70 days. School would commit to teaching the 


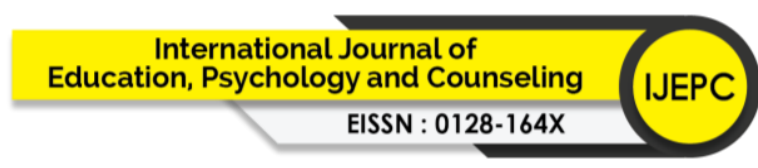

Volume 6 Issue 42 (September 2021) PP. 111-132

DOI 10.35631/IJEPC.642010

complete program in only one grade for 30 students no intervention or monitoring for the remaining 30 students.

Students' average age was 18 years $\measuredangle \mathrm{SD} \_1$, range 17.8-18.3. Students not enrolled in BTE served 17.8years. Socioeconomic indicators were not collected for individual as comparison classrooms. All students in BTE classrooms participated in the program. All the students participating in the BTE program were in a group on Telegram and were given regular instructions. Also, the second group was not given any instruction.

Informed consent from parents and student assent were required for students to participate in the program evaluation. Hundred percent $(\mathrm{N}=60)$ of the twelfth-grade students (ns= respectively; $50 \%$ female and $50 \%$ male) from had parental permission to participate.

Approximately $36 \%$ of participating students were female in the BTE group $(n=30)$ and $36 \%$ were in the comparison group $(n=30)$. Permission rates did not differ by condition, pN0.05. The two groups of classrooms (BTE and unmonitored) were comparable in terms of ethnicity $\left(\chi^{2}(3)=0.13, \mathrm{pN} 0.05\right)$ and gender $\left(\chi^{2}(1)=0.56, \mathrm{pN} 0.05\right)$. Students' average age was 18 years ( $\mathrm{SD}=1$, range 17.8 to 18.3 years). Socioeconomic indicators were not collected for individual students. All students in BTE program participated in the program as it was integrated along with the regular curriculum and exam schedule. No changes were made in the school schedule because of the activities or program.

\section{Materials and Procedure}

The institutional review board of the authors' university approved all materials and procedures. Program evaluation.

The program evaluation extended across 70 days and post 30 days after the program was over and included two time check points using psychometric and EEG at the start of the program (pre-test) and immediately after 10 weeks at the end of the BTE program (post-test). A pre-test (about one week prior to training) and post-test (ten weeks into teaching BTE) online behavioural assessments on each student with parental consent, which included ratings on each student's social and emotional competence.

\section{Informed Consent Procedures}

The parents of students in each classroom received a letter signed by the superintendent and the principal investigator describing the evaluation project as well as an informed consent letter to sign. Parents who agreed to let their child participate returned the completed informed consent form to their child's teacher.

\section{Training Procedure}

Teachers in both conditions (BTE, comparison) participated in a one-hour overview of emotional literacy and validation of the task. Individual Teachers were assigned to two students who were responsible for the validation and progress of the assigned students of the BTE group. Overall, 15 teachers were assigned for 30 students.

The Comparison group was unmonitored. Teachers in classrooms assigned to validate students' activities also participated in a highly interactive training that lasted one hour. Teachers in the BTE training learned how to validate the activities and received a detailed, easy-to-follow 


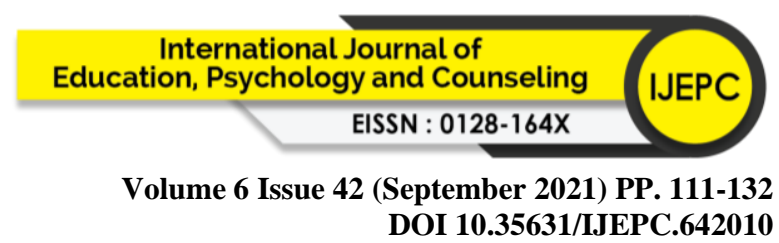

teaching manual. The manual provided validation methods and troubleshooting with different situations since the program were online. During the training, teachers observed sample validation and worked in small groups to help each overcome the difficulties as a cohort.

The trainers and teachers observed the activities and offered feedback and suggestions for best practices throughout the course. Finally, the trainers assisted the teachers in mapping out the integration of BTE cross the training period. Logical Reasoning quizzes were held on telegram using BOT with automatic ranking for a period of 8 weeks as the students had prelims and examinations for 2 weeks.

\section{Quality Assurance}

This study was designed as a pilot effectiveness study to examine the impact of BTE in real world conditions with minimal contact with the program developers. The research team visited the schools two times throughout the program to meet with teachers and who were validating the BTE. The goal of the meetings was to answer questions from the teachers and to review student's participation to ensure that the program was being implemented properly. The principal of the school also reviewed each teacher's validation and motivating students regularly to ensure BTE activities lessons were being implemented. By the end of the program, all teachers had completed at least 10 weeks of validation of the BTE activities (an estimated 10 online lectures).

\section{Measures}

\section{Social And Emotional Competence}

\section{The MAAS}

The MAAS is a 15-item scale designed to assess a core characteristic of dispositional mindfulness, namely, open or receptive awareness of and attention to what is taking place in the present. The scale shows strong psychometric properties and has been validated with college, community, and cancer patient samples. Correlational, quasi-experimental, and laboratory studies have shown that the MAAS taps a unique quality of consciousness that is related to, and predictive of, a variety of self-regulation and well-being constructs. The measure takes 10 minutes or less to complete. (Brown, K.W. \& Ryan, R.M. (2003)

\section{The Perceived Stress Scale}

It was developed to measure the degree to which situations in one's life are appraised as stressful. Psychological stress has been defined as the extent to which persons perceive (appraise) that their demands exceed their ability to cope. ( Cohen, S., \& Janicki-Deverts, D. (2012)

\section{The Healthy Self-Regulation scale (West, 2008)}

It is a set of items that originated as a subscale of the Mindfulness Thinking and Acting Scale for Adolescence (MTASA). The MTASA is an adolescent mindfulness measure developed by West (2008). West suggests that these 12 items may be used as an independent, self-report measure (A. West, personal communication, December 7, 2008). When the items were extracted from the MTASA and examined, West found that the HSR scale had good internal consistency and positive correlations with a variety of wellness indicators. 


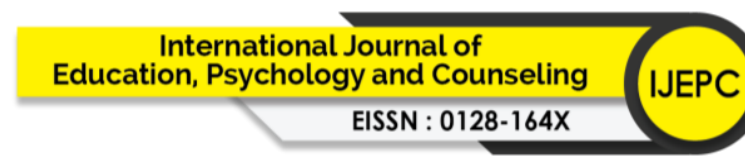

Volume 6 Issue 42 (September 2021) PP. 111-132

DOI 10.35631/IJEPC.642010

In addition to this instrument's strong internal consistency and positive correlations with wellness indicators, West (2008) found the HSR to have strong test-retest reliability (0.84). The HSR items were chosen for use as a scale in the proposed research based on the measure's short length, readability, and hypothesized relationship to healthy self-regulation. Selfregulation has been associated, in research conducted within youth populations, with the ability to regulate substance use, sexual behaviour, and academic achievement (Miller \& Byrnes, 2001; Raffaelli \& Crockett, 2003; Wills, Sandy, \& Yaeger, 2002).

\section{Rosenberg Self-Esteem Scale (RSE)}

The Rosenberg Self-Esteem Scale (Rosenberg, 1965) is a 10-item questionnaire that uses a 4point Likert scale (1, 2, 3, 4; Strongly Agree, Agree, Disagree, Strongly Disagree) to answer each item. The RSE was developed and tested on 5,024 high school juniors and seniors from 10 randomly selected schools in New York State (Rosenberg, 1965). A score from 0-30 is achievable, with higher scores indicating higher self-esteem.

\section{Teen Conflict Survey Impulsiveness Subscale (IMP)}

The impulsiveness subscale of the Teen Conflict Survey (Bosworth \& Espelage, 1995) is a 4item questionnaire that uses a 5-point Likert scale (a, b, c, d, e; Never, Seldom, Sometimes, Often, Always) to measure the frequency of impulsive behaviours. This survey was developed and tested on middle school students grades 6-8 (Bosworth \& Espelage, 1995). A score from 5-25 is achievable, with higher scores indicating higher impulsiveness.

\section{Quality of Life (QOL)}

The Vitality Subscale of the Short Form-36 Quality of Life scale (MOS-36) is a 9-item questionnaire that uses a 6-point Likert scale $(1,2,3,4,5,6$; All of the time, most of the time, A good bit of the time, some of the time, a little of the time, none of the time) to measure general vitality and psychological well-being. This survey was developed out of the original medical outcome survey from the RAND Corporation.

\section{The Internalizing Subscale (SRSS-I6)}

It is subscale of the Student Risk Screening Scale for Internalizing and Externalizing (SRSSIE) with the internalizing subscale of the Teacher Report Form (TRF; Achenbach, 1991).

\section{QEEG}

Brain-computer interface (BCI) systems use neural activity to control signals, but this is only possible after training specific cortical activity patterns. Computer assisted learning is characterized by two concepts, respectively flow zone and shaping. 


\section{Emotive Insight}

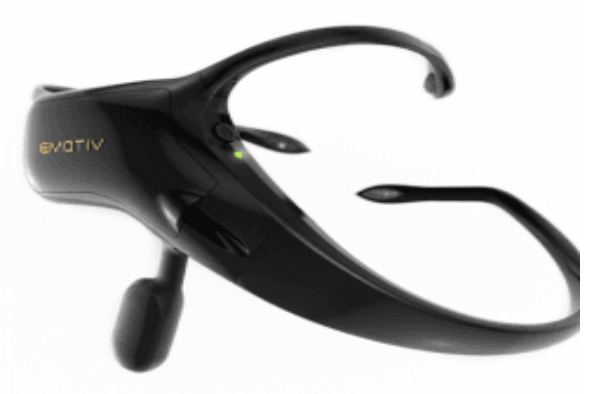

Figure 1

Emotive Insight is designed for everyday use with advanced electronics that produce clean and robust signals, uses five channel EEG that senses brain activity. Semi-dry polymer sensors are easy to use and clean. Minimal setup time is only about two minutes. This device works wirelessly. You may connect your computer or mobile phone. This device lasts for up to nine hours. To detect head movements nine-axis motion sensors are available.

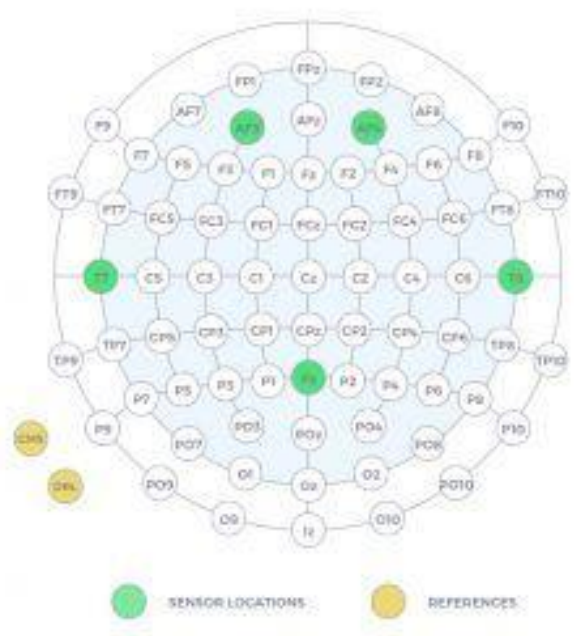

Figure 2

There are five EEG sensors to sense brain activity and two CMS/DRL references (left/right mastoid process alternative). CMS (Common Mode Sense) is an active electrode and DRL (Driven Right Leg) is a passive electrode.

Green sensors are located in the frontal, temporal and parietal part of the head. The yellow sensors are the basic electrode connected to the reference electrode. 


\section{$E=\frac{\beta}{(\alpha+\theta)}$}

\section{Figure 3. Engagement Formula}

The psychologist Csikszentmihalyi introduced the notion of flow zone, meaning that the difficulty of a task is in balance with the individual's capability to be engaged without getting stressed or bored. The concept of shaping was identified by a researcher, Skinner, and it represents the repetitive process through which performance is refined. The individual will gradually perform complex tasks with high precision. Neurophysiological signals triggered by an EEG based learning environment were tested in Germany and it resulted in students can adapt better to the learning content, improving in this way their efforts and the context did lead to good results.

Table 1: EEG Bands Specification

\begin{tabular}{lll}
\hline EEG Bands & Frequency $(\mathbf{H z})$ & Mental States \\
\hline Alpha & $7-13$ & Relaxed, conscious \\
Beta & $13-30$ & $\begin{array}{l}\text { Relaxed, but } \\
\text { focused, thinking, } \\
\text { alerted } \\
\text { Creative, dream }\end{array}$ \\
& & C-7
\end{tabular}

An EEG headset was found to be useful to determine if there exists the need of medical intervention for the students who suffer due to anxiety. Along with the EGG data, behaviour and respiratory data played a key role. Breathing deeply enhances attention and proper brain electrical activity modulation which is required during the learning process. The paper's system is dedicated to analyse the student performance during the online learning process, while being exposed to three ways of notion presentation, namely text; text and illustrations, including charts; and video. The collaboration between teachers, students and parents is desired in order to improve their education and well-being.

The gadgets which are used in the system are an Emotive Insight headset, along with a computer or a mobile phone. The headset exchanges data with the computer and mobile phone via Bluetooth. The Emotive BCI program is installed on the computer, and it helps the user to place the headset for functioning in optimal conditions by analysing the contact quality between the EEG electrodes and the user's head. The electrodes can get dry and cause a lower signal to noise ratio that would trigger a low prediction accuracy. Contact lens fluid or saline can be put on the electrodes for improved results.

The mobile application determines based on the brainwaves which are the numerical values for "Focus, Stress, Relaxation, Engagement, Excitement and Interest". The values are introduced manually into the system's web application, along with data about daily activities, and their learning and evaluation processes. The student has access to different study materials that can involve just text; text and illustrations, but also videos, while using the Emotiv Insight headset. 
Volume 6 Issue 42 (September 2021) PP. 111-132

DOI 10.35631/IJEPC.642010

The data transfer between the user's computer/mobile phone and the system server is done via a route that includes a firewall to define rules which determine forbidden inbound and outbound traffic that passes through the ports of the system.

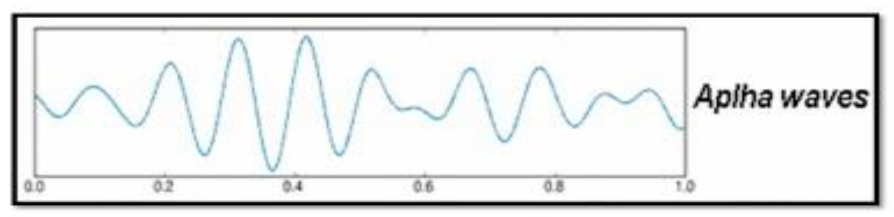

Figure 4. Alpha Wave Representation

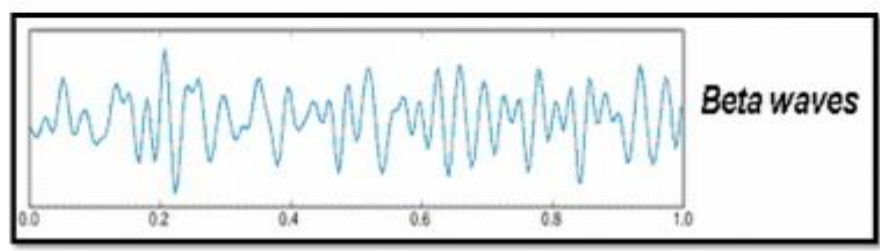

Figure 5. Beta Wave Representation

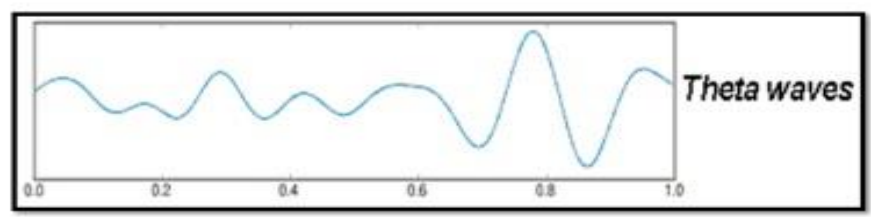

Figure 6. Theta Wave Representation

Psychometric Analysis and QEEG reports from the Behavioural Assessment System for Children (BASC) were used for a global behavioural assessment of social and emotional competence (Reynolds \& Kamphaus, 1992). The BASC is a comprehensive multidimensional assessment that has been normed on large representative samples as well as clinical samples.

The scales demonstrate high internal consistency and test-retest reliability (Reynolds \& Kamphaus, 1992). Each survey was labelled with the name of a participating student and Pre and Post Results indicated the extent to which each student in their class engaged in each of 11 behaviours (e.g. "Self-Regulation", Focus, Attention, engagement) using a four-point Likerttype scale where $0=$ never, $1=$ sometimes, $2=$ often, and $3=$ always. Psychometric Analysis comprise four primary composite scales reflecting externalizing problems (e.g., hyperactivity, aggression, and conduct problems), internalizing problems (e.g., anxiety, depression, and somatization), school problems (e.g., attention problems, learning problems), and adaptability (e.g., social skills, leadership, and study skills).

Student grades for the academic term were obtained from report cards of the exam given immediately post the program. 


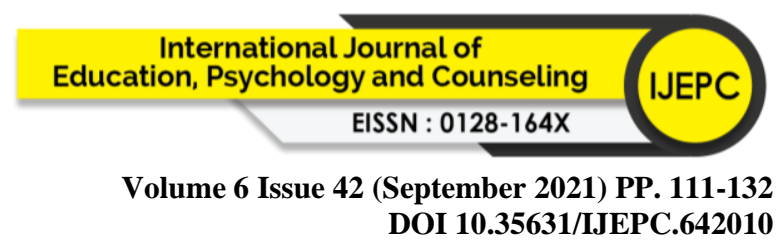

\section{Analysis Plan}

\section{Missing Data}

We conducted chi square tests to examine incomplete versus complete data in BTE group and comparison for the psychometric at each time point and for program end grades. No differences in missing data were found for either time point on the Psychometric Analysis and QEEEG; however, there was a significant difference in missing data for program-end grades with students in the comparison and BTE program group being more likely to have missing data, $\chi 2$ $(1)=12.52, \mathrm{pb} 0.001$.

\section{Primary Analyses}

To examine the impact of BTE, a quasi-experimental design (adjusting for prior differences between groups) was utilized. Although the intervention was assigned at the level of school in only $12^{\text {th }}$ Class (High school), the analyses were structured at the student level. Due to the limited students of school and restrictions because of Covid in this study, the non-independence in the design cannot be addressed in hierarchical linear modelling (HLM), the ideal analytic tool for nested data (Raudenbush \& Bryk, 2002). Thus, the results presented here may represent inflated estimates of statistical significance and effect size. Like other preliminary, schoolbased quasi-experiments (e.g., Aber, Jones, Brown, Chaudry, \& Samples, 1998; Caplan et al., 1992), we employed repeated measures for most analyses with condition as the independent variable and student scores as a covariate (Tabachnick \& Fidell, 2001). Planned contrasts for group (BTE, comparison) by time (pre-test, post-test) interaction effects tested the hypothesis that at post-test, mean differences between the groups existed.

\section{Results}

Table 2: Descriptive Analyses: Adjusted Means And Standard Deviation Of Groups At Pre And Post Test

Group (Intervention)

\begin{tabular}{llllll}
\hline BASC & ADJ M & SD & ADJ M & SD & t(diff) \\
\hline & $\underline{\text { Pre test }}$ & & $\underline{\text { Post test }}$ & & \\
Internalizing & 582.5 & 70 & 1048 & 586.9 & +465.5 \\
Externalizing & 653.7 & 558.1 & 579 & 446.1 & -74.67 \\
Adaptive skills & 1439 & 320.5 & 1732.3 & 257.4 & +293.25 \\
School Problem & $\mathbf{1 2 1 6 . 3}$ & $\mathbf{2 4 5 . 7}$ & $\mathbf{1 4 5 2}$ & $\mathbf{3 0 0 . 6}$ & $\mathbf{+ 2 3 5 . 7 5}$ \\
\hline
\end{tabular}

Group (Control)

\begin{tabular}{llllll}
\hline BASC & ADJ M & SD & ADJ M & SD & t(diff) \\
\hline & $\underline{\text { Pre test }}$ & & $\underline{\text { Post test }}$ & & \\
Internalizing & 563 & 26.87 & 486.5 & 30.4 & -76.5 \\
Externalizing & 443 & 165.7 & 373.3 & 146.1 & -69.67 \\
Adaptive skills & 856.5 & 471.9 & 810.5 & 385.5 & -46 \\
School Problem & $\mathbf{8 7 0 . 3}$ & $\mathbf{4 0 2 . 8}$ & $\mathbf{8 2 9 . 3}$ & $\mathbf{3 0 8 . 8}$ & $\mathbf{- 4 1}$ \\
\hline
\end{tabular}

Note: ADJ M means adjusted mean; SD means standard deviation; t(diff) means difference in the value of post and pre; BASC means Behaviour Assessment System for Children. 


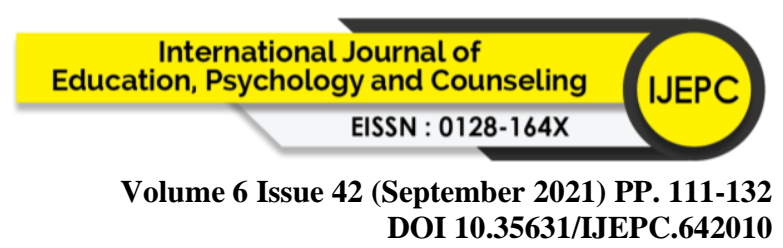

- Internalizing: self-esteem and internalizing

- Externalizing: EEG SCORE (excitement), impulsivity, externalizing.

- Adaptive skills: EEG SCORES (interest, relaxation, stress), mindfulness

- School problems: EEG SCORES (engagement, focus), stress and self-regulation

The adjusted means and standard deviations for each time point for both conditions are summarized in Table 2. At pre-test, there was an overall difference in the two groups intervention and comparison. Specifically, students in the BTE group had higher internalizing than students in the comparison group, standard deviation $t$ (diff) is -465.5 . To identify significant change from pre-test to post-test for each condition, we conducted paired sample ttests for each of the outcome variables.

In the comparison group, Mindful Gurukul and students' self-reports of adaptive, internalizing, externalizing and school problems decreased over time, For the BTE group, Mindful Gurukul`s reports of school problems, adaptive skills and internalizing problems also increased over time than there were no significant changes in externalizing. The BTE group also had a significant increase internalizing.

Table 3: Adjusted Means and Standard Deviation of Logical Reasoning Quizzes for 8 Weeks

\begin{tabular}{lccc}
\hline week & marks & mean & t(diff) \\
\hline 1 & 1050 & 35 & -33.96 \\
2 & 1800 & 60 & -8.96 \\
3 & 1870 & 62.33 & -6.63 \\
4 & 1950 & 65 & -3.96 \\
5 & 2040 & 68 & -0.96 \\
6 & 2250 & 75 & 6.04 \\
7 & 2690 & 89.67 & 20.71 \\
8 & 2900 & 96.67 & 27.71 \\
\hline
\end{tabular}

Note: Week: number of weeks, Marks: Total marks obtained by students in 8 weeks in logical reasoning test, Mean: average marks of students; $t$ (diff): standard deviation.

Table 3 shows that scores show the standard deviation $t$ (diff) in respect to the scores obtained during weekly logical reasoning quizzes held for the period of 8 weeks. The $t$ (diff) increased from -33.96 to 27.71 with a gradual improvement in the scores with progressing weeks. 


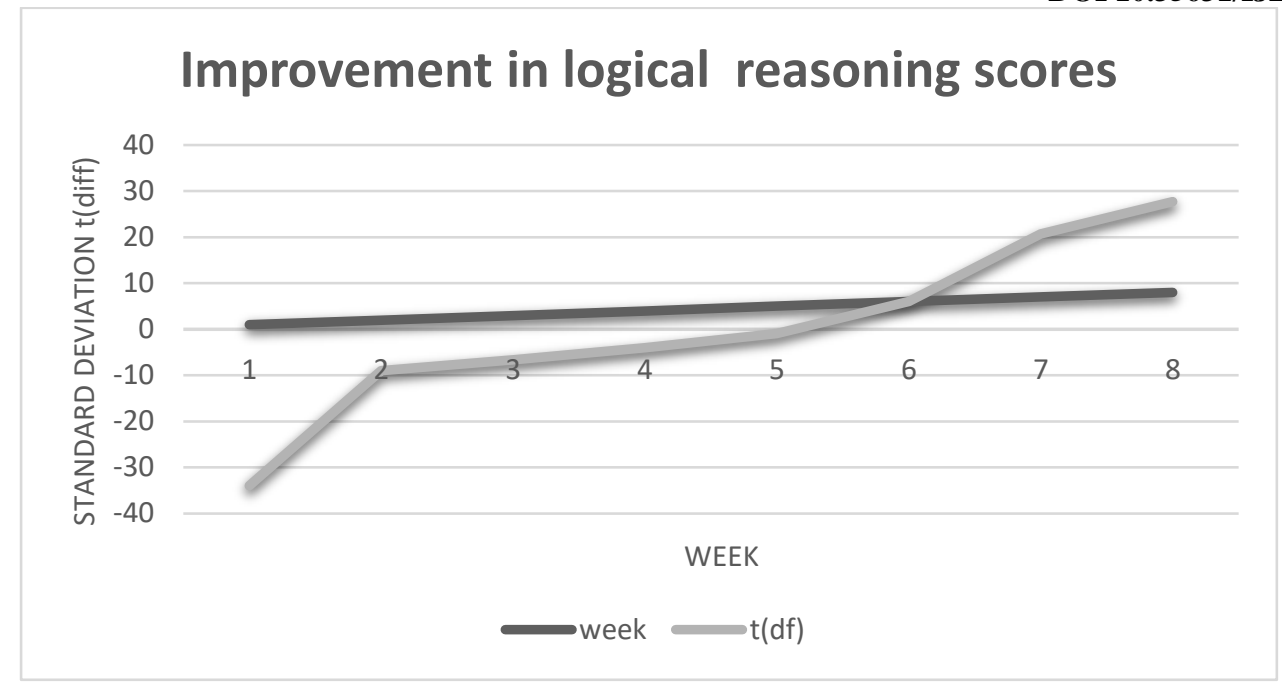

Figure 2

Note: Figure 2 shows the graphical representation as the BTE program progressed steady improvement was seen in the BTE group. The comparison group was however not subjected to these exams as no interventions was planned for them and were not inclined to participate in these logical reason quizzes.

\section{Discussion}

This study provides preliminary data supporting the effectiveness of the BTE Program. Consistent with our hypotheses, students in classrooms using BTE had higher academic performance in their Prelims examinations as well as higher social and emotional competence in some areas compared to students not using BTE. The small to moderate effect sizes in this study are consistent with those reported in the literature (Durlak et al., in press).

Psychometric ratings indicated that at post-test, students in BTE classrooms, compared to those in the comparison group, had higher adaptability scores, which reflect ratings of behaviours related to positive relationships, leadership, and studying, and especially with lower scores on school problems, which reflect ratings of behaviours related to attention and learning problems. No differences emerged among psychometric ratings of the behaviours reflective of possible clinical disorders such as anxiety and depression or aggression and hyperactivity, which is not unexpected given that we evaluated this intervention after only two and half months. Interventions impacting these outcomes tend to be more intensive and incorporate coaching at an individual or small-group level (Bierman \& Welsh, 1997).

The results of this preliminary effectiveness evaluation suggest that BTE has impact on students' academic and social outcomes. As a part of the curriculum, students can understand and realize their own emotions and the emotions of others, including family members and characters in literature. The activities involving regular mindfulness brings a disciplined, coordinated and short episode of calmness and stability in young adults. The activities involving regular study hours and exercise seem doable and easy leading to better compliance. The differences between student's Prelim grades in the BTE versus comparison classrooms are promising and in the predicted direction. However, because BTE is activity-intensive it is possible that the differences between the two groups may be linked to more opportunities and availability to regularly complete activity leading to the development of the BTE skills. Current investigations in our laboratory support the hypothesis that BTE enhances the development of BTE skills, which positively influence student performance in academic Examinations. 


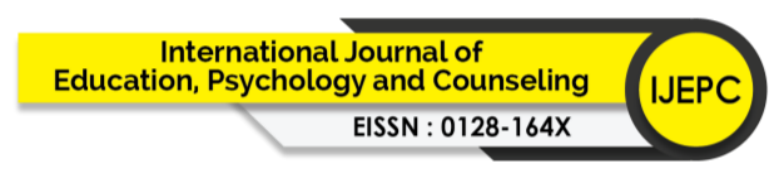

Volume 6 Issue 42 (September 2021) PP. 111-132

DOI 10.35631/IJEPC.642010

With respect to study habits and social competence, many aspects of the program (journaling) focuses on problem solving about difficult emotional situations, future planning and perspective-taking, teaching students to consider how their emotions and behaviour affect others. With this knowledge, students may be less likely to behave in ways that are disruptive and may be better able to regulate their emotions in order to focus on academic tasks. Moreover, the lessons are designed to engage students in learning; when students are more engaged, they are more likely to pay attention and apply themselves to school work (National Research Council and the Institute of Medicine, 2004). The present study provides preliminary evidence of this possibility, at least within the subject in which it is being taught.

Although these results are promising, and we acknowledge the limitations of this study. Students not schools, were assigned to intervention group (BTE, comparison); however, the analyses were conducted at the student level. As a pilot test of the effectiveness of BTE, recruiting a sample large enough to conduct a clustered randomized trial and randomizing at the classroom or school level was not feasible. Thus, the analyses do not account for the independence of the students who were at home since it was during Covid epidemic and not clustered within classrooms within schools, with randomization being assigned at the level of the classroom. The consequence of conducting the analyses without addressing the nested design is that estimates of statistical significance and effect size may be inflated (see Raudenbush \& Bryk, 2002).

Although the results suggest that BTE holds promise for impacting student outcomes, they should be interpreted as preliminary until replicated with a clustered randomized design. Moreover, although the student sample was diverse racially and ethnically, the design of the study did not permit analyses of the independent influences of gender, race, ethnicity, socioeconomic background, and neighbourhood type (e.g., inner-city versus suburban). Examining individual student differences would help to establish the cultural appropriateness of BTE program as well as to examine the extent to which BTE may be more or less effective for students of different genders and backgrounds (Rotheram-Borus \& Tsemberis, 1989). BTE is a multi-year program intended to begin in during the school years when competitive exams are held and are designed post 15 years of age of the participant. This evaluation examined its effects after just two and half months of implementation.

One would expect the findings reported here to become stronger as students participate in ongoing lessons and schools both adopt BTE for all crucial grade when exit exams are held. Examining dosage effects and quality of implementation on academic, social, and emotional outcomes would help to identify the optimal level of emotional literacy training necessary to maximize positive student outcomes (Greenberg, Domitrovich, Graczyk, \& Zins, 2004).

Through the various activities assigned, BTE teaches students to both be aware of the causes and consequences of the negative emotions that they encounter, such as those that arise from being alienated or preparing for a difficult test, and how to identify resources to help them cope with their feelings, such as asking a teacher, parent, or classmate for assistance. Students who are skilled emotionally tend to experience more positive emotions and have higher psychological well-being (Brackett \& Mayer, 2003; Lopes, Salovey, \& Straus, 2003). Future work examining the mediating factors between BTE and both academic achievement and social competence would allow us to test this hypothesis. Further, examining if and how BTE affects 


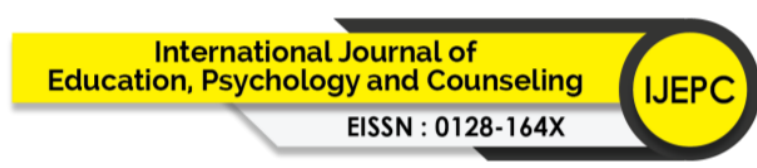

Volume 6 Issue 42 (September 2021) PP. 111-132

DOI 10.35631/IJEPC.642010

life quality is a worthwhile next step for understanding the processes by which BTE impacts student outcomes.

It is possible that integrating SEL programming into schools has a reciprocal benefit by helping to create greater engagement in and connection to school among students (and teachers), which are important for academic success. For example, other research shows that when students feel connected to school, their grades improve, they become less disruptive in class, and they are more likely to aspire to higher educational goals (Christenson \& Harvey, 2004; Stipek, 2005).

Future effectiveness trials of BTE will incorporate additional objective academic criteria, such as standardized test scores, which have the potential to provide more adequate experimental control for potential expectancy effects on student grades and ratings of students' social and emotional competence. Teachers assign grades to students, but they also are the implementers of the intervention and are participating in professional development as they learn how to use the activities for their benefit; this may have affected how they enhance and increase the longevity of the positive influence on students.

Observational measures of student and teacher behaviour also may provide more objective data for evaluating the impact of BTE on the learning and social climate of the classroom. The social processes within a classroom setting, including the extent to which teachers and students interact with each other in ways that are supportive, caring, and empowering, may prove to be a significant mediator of the effect of classroom interventions on student outcomes (Tseng \& Seidman, 2007). Additionally, the theoretical foundation for BTE sits that the skills of emotional literacy (realise, raise an anchor, rewire and redefine) help students make informed decisions about engaging in risky behaviours; thus, future research might examine the impact of BTE on other important criteria, such as substance abuse and bullying, (e.g., Johnston, O'Malley, Bachman, \& Schulenberg, 2005).

\section{Conclusion}

Successful schools ensure that all students master basic academic skills but BTE skills, such as engagement and self-regulation are essential for achieving success at competitive examinations which ae extremely stressful and challenging. The number of students are very high and the successful candidates are mere minimum leading to a funnel creating severe pressure both the parents and students. However, most educators and parents support a broader educational agenda - one that involves enhancing students' social-emotional competencies (Greenberg et al., 2003).

Economists are calling for a greater focus on these non-cognitive skills, proclaiming that the greatest returns on education investments are "from nurturing children's non-cognitive skills, giving them social, emotional and behavioural benefits that lead to success later in life..." (Committee for Economic Development, 2004). James Heckman, Nobel Laureate in Economics, argues that investments in social and emotional learning contribute to the quality and productivity of the workforce by increasing motivation, perseverance, and self-control (Heckman \& Masterov, 2004).

In fact, the common element among schools reporting an increase in academic success, improved quality of interpersonal relationships between teachers and students, and a decrease in problem behaviour, is a systematic process for promoting SEL (Elias et al., 1997). Although 


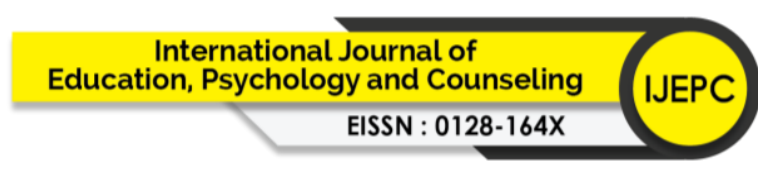

Volume 6 Issue 42 (September 2021) PP. 111-132 DOI 10.35631/IJEPC.642010

educators are aware of the importance of attending to the social and emotional development of children, school systems often are hesitant to integrate programs for which they cannot predict clear, discernible benefits for students' academic progress and school behaviour. The case for teaching social and emotional skills, and emotional literacy, in particular, is stronger when accompanied by empirical evidence connecting the enhancement of these skills to academic and social outcomes. There is good reason to believe that programs teaching social and emotional skills will be of value in achieving school goals (cf. Greenberg et al., 2003; Mayer $\&$ Cobb, 2000). The present study provides preliminary evidence supporting the importance of incorporating lessons on emotions and emotion related concepts into existing curriculum.

\section{Acknowledgments}

We appreciate those who read early drafts of the manuscript and provided invaluable feedback, and those who assisted us in data collection. We especially wish to thank Jappreet Sethi, as well as students and teachers for actively participating in the program.

\section{References}

Abel, H. S. (2005). The evaluation of a stress management program for graduate students. Unpublished doctoral dissertation, Texas A\&M University, Corpus Christi, TX. Retrieved from ProQuest Dissertations and Theses (www.proquest.com).

Adlaf, E. M., Gliksman, L., Demers, A., \& NewtonTaylor, B. (2001). The prevalence of elevated psychological distress among Canadian undergraduates: Findings from the 1998 Canadian campus survey. Journal of American College Health, 50(2), 67-72.

American College Health Association. (2011). American College Health Association-National College Health Assessment II: Reference Group Data Report Spring 2011. Hanover, MD: Author.

Anderson, L. A., \& Whiston, S. C. (2005). Sexual assault education programs: A meta-analytic examination of their effectiveness. Psychology of Women Quarterly, 29(4), 374-388. Astin, A. J. (1997). Stress reduction through mindfulness meditation: Effects on psychological symptomatology, sense of control, and spiritual experiences. Psychotherapy and Psychosomatics, 66(2), 97-106. Astin, A. W. (1984). Student involvement: A developmental theory for higher education. Journal of College Student Personnel, 25(4), 297-308.

Baker, N. C. (2012). Does daily meditation or coherent breathing influence perceived stress, stress effects, anxiety, or holistic wellness in college freshmen and sophomores? Unpublished doctoral dissertation, Boston College. Retrieved from ProQuest Dissertations and Theses (www. proquest.com).

Bar-On, R., Handley, R., \& Fund, S. (2006). The impact of emotional intelligence on performance. In V. U. Druskat, F. Sala, \& G. Mount (Eds.), Linking emotional intelligence and performance at work (pp. 3-19). Mahwah, NJ: Erlbaum.

Bayram, N., \& Bilgel, N. (2008). The prevalence and socio-demographic correlations of depression, anxiety and stress among a group of university students. Social Psychiatry and Psychiatric Epidemiology, 43(8), 667-672.

Beck, A. T., Emery, G., \& Greenberg, R. L. (1985). Anxiety disorders and phobias: A cognitive perspective. New York: Basic Books.

Botvin, G. J. (2000). Preventing drug abuse in schools: Social and competence enhancement approaches targeting individual-level etiologic factors. Addictive Behaviors, 25(6), 887-897. 


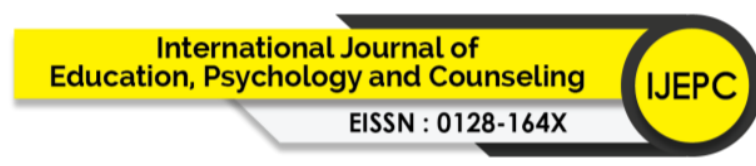

Volume 6 Issue 42 (September 2021) PP. 111-132

DOI 10.35631/IJEPC.642010

Braithwaite, S. R., \& Fincham, F. D. (2007). ePREP: Computer based prevention of relationship dysfunction, depression, and anxiety. Journal of Social and Clinical Psychology, 26(5), 609-622.

Braithwaite, S. R., \& Fincham, F. D. (2009). A randomized clinical trial of a computer based preventive intervention: Replication and extension of ePREP. Journal of Family Psychology, 23(1), 32-38.

Braithwaite, S. R., \& Fincham, F. D. (2011). Computer-based dissemination: A randomized clinical trial of ePREP using the actor partner interdependence model. Behaviour Research and Therapy, 49(2), 126-131.

Burns, D. D. (1999). Feeling good: The new mood therapy. New York: Avon Books.

Carey, K. B., Scott-Sheldon, L. A., Carey, M. P., \& DeMartini, K. S. (2007). Individual-level interventions to reduce college student drinking: A meta-analytic review. Addictive Behaviors, 32(11), 2469-2494.

Catalano, R. F., Berglund, M. L., Ryan, J. A. M., Lonczak, H. S., \& Hawkins, J. D. (2004). Positive youth development in the United States: Research findings on evaluations of positive youth development programs. Prevention and Treatment, 5(1), 98-124.

Charlesworth, E. A., Murphy, S., \& Beutler, L. E. (1981). Stress management skill for nursing students. Journal of Clinical Psychology, 37(2), 284-290.

Collaborative for Academic, Social, and Emotional Learning (CASEL). (2003). Safe and sound: An educational leader's guide to evidence-based social and emotional learning (SEL) programs. Chicago: Author.

Collaborative for Academic, Social, and Emotional Learning (CASEL). (2012). 2013 CASEL guide: Effective social and emotional learning programs-Preschool and elementary school edition. Chicago: Author.

Conley, C. S., Durlak, J. A., \& Dickson, D. A. (2013). An evaluative review of outcome research on universal mental health promotion and prevention programs for higher education students. Journal of American College Health, 61(5), 286-301.

Conley, C. S., Durlak, J. A., \& Kirsch, A. C. (in press). A meta-analysis of universal mental health prevention programs for higher education students. Prevention Science.

Deckro, G. R., Ballinger, K. M., Hoyt, M., Wilcher, M., Dusek, J., Myers, P., et al. (2002). The evaluation of a mind/body intervention to reduce psychological distress and perceived stress in college students. Journal of American College Health, 50(6), 281-287.

Durlak, J. A. (1997). Successful prevention programs for children and adolescents. New York: Plenum Press.

Durlak, J. A., Schellinger, K. B., Weissberg, R. P., Dymnicki, A. B., \& Taylor, R. D. (2011). The impact of enhancing students' social and emotional learning: A meta-analysis of school-based universal interventions. Child Development, 82(1), 405-432.

Easwaran, E. (1978). Meditation: Commonsense directions for an uncommon life. Petaluma, CA: Nilgiri Press.

Easwaran, E. (1991). Meditation: A simple eightpoint program for translating spiritual ideals into daily life (2nd ed.). Tomales, CA: Nilgiri Press.

Elias, M. J., Zins, J. E., Weissberg, R. P., Frey, K. S., Greenberg, M. T., Haynes, N. M., et al. (1997). In J. O’Neil, J. Houtz, J. A. Jones, \& K. Peck (Eds.), Promoting social and emotional learning: Guidelines for educators. Alexandria, VA: Association for Supervision and Curriculum Development.

Ellis, A. (2001). Overcoming destructive beliefs, feelings, and behaviors: New directions for rational emotive behavior therapy. Amherst, NY: Prometheus Books. 


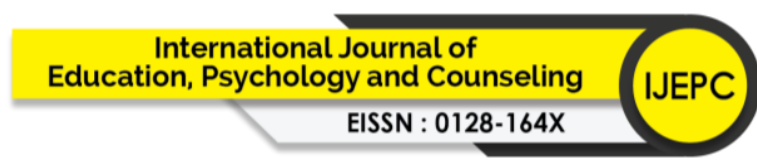

Volume 6 Issue 42 (September 2021) PP. 111-132

DOI 10.35631/IJEPC.642010

Eppley, K. R., Abrams, A. I., \& Shear, J. (1989). Differential effects of relaxation techniques on trait anxiety: A meta-analysis. Journal of Clinical Psychology, 45(6), 957-974.

Epstein, E. M., Sloan, D. M., \& Marx, B. P. (2005). Getting to the heart of the matter: Written disclosure, gender, and heart rate. Psychosomatic Medicine, 67, 413-419.

Evans, N. J., Forney, D. S., Guido, F. M., Patton, L. D., \& Renn, K. A. (2009). Student development in college theory, research, and practice. San Francisco: Wiley.

Fulton, M. A. (1990). The effects of relaxation training and meditation on stress, anxiety, and subjective experience in college students. Unpublished doctoral dissertation, Lehigh University, Bethlehem, PA. Retrieved from ProQuest Dissertations and Theses (www.proquest.com).

Gerdes, H., \& Mallinckrodt, B. (1994). Emotional, social, and academic adjustment of college students: A longitudinal study of retention. Journal of Counseling and Development, 72(3), 281- 288.

Gloria, A., \& Ho, T. (2003). Environmental, social, and psychological experiences of Asian American undergraduates: Examining issues of academic persistence. Journal of Counseling and Development, 81, 93-105.

Grassi, A., Preziosa, A., Villani, D., \& Riva, G. (2007). A relaxing journey: The use of mobile phones for well-being improvement. Annual Review of CyberTherapy and Telemedicine, 5, 123-131.

Greenberg, M. T., Domitrovich, C., \& Bumbarger, B. (2001). The prevention of mental disorders in school-aged children: Current state of the field. Prevention and Treatment, $4(1), 1-62$.

Greenberg, M. T., Weissberg, R. P., O’Brien, M. U., Zins, J. E., Fredericks, L., Resnik, H., et al. (2003). Enhancing school-based prevention and youth development through coordinated social, emotional, and academic learning. American Psychologist, 58(6/7), 466-474.

Gresham, F. M. (1995). Best practices in social skills training. In A. Thomas \& J. Grimes (Eds.), Best practices in school psychology (Vol. 3, pp. 1021-1030). Washington, DC: National Association of School Psychologists.

Heaman, D. (1995). The quieting response (QR): A modality for reduction in psychophysiologic stress in nursing students. Journal of Nursing Education, 34(1), 510.

Hefner, J. L., \& Eisenberg, D. (2009). Social support and mental health among college students. American Journal of Orthopsychiatry, 79(4), 491-499.

Hoffmann Gurka, A. C. (2005). Mindfulness meditation for college students: A study of its utility and promotion of its practice post treatment. Unpublished doctoral dissertation, Marquette University, Milwaukee, WI. Retrieved from ProQuest Dissertations and Theses (www.proquest. com).

Howard, D. E., Schiraldi, G., Pineda, A., \& Campanella, R. (2006). Stress and mental health among college students: Overview and promising prevention intervention. In M. V. Landow (Ed.), SEL in Higher Education 211 Stress and mental health of college students (pp. 91-123). New York: Nova Science.

Jones, L. V. (2004). Enhancing psychosocial competence among black women in college. Social Work, 49(1), 75-84.

Jordan, P. J., \& Ashkanasy, N. M. (2006). Emotional intelligence, emotional self-awareness, and team effectiveness. In V. U. Druskat, F. Sala, \& G. Mount (Eds.), Linking emotional intelligence and performance at work (pp. 145-163). Mahwah, NJ: Erlbaum. 


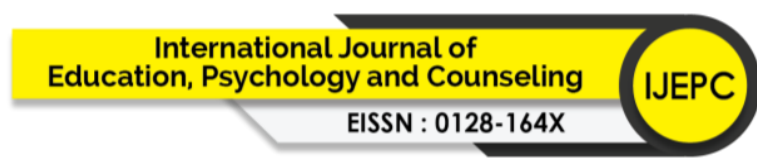

Volume 6 Issue 42 (September 2021) PP. 111-132

DOI 10.35631/IJEPC.642010

Kabat-Zinn, J. (1982). An outpatient program in behavioral medicine for chronic pain patients based on the practice of mindfulness meditation: Theoretical considerations and preliminary results. General Hospital Psychiatry General Hospital Psychiatry, 4(1), 3347.

Kabat-Zinn, J. (1990). Full catastrophe living: Using the wisdom of your body and mind to face stress, pain, and illness. New York: Delacorte Press.

Kanji, N., White, A., \& Ernst, E. (2006). Autogenic training to reduce anxiety in nursing students: Randomized controlled trial. Journal of Advanced Nursing, 53, 729-735.

Kindlon, D. J. (1983). Comparison of use of meditation and rest in treatment of test anxiety. Psychological Reports, 53(3), 931-938.

Leggett, D. K. (2010). Effectiveness of a brief stress reduction intervention for nursing students in reducing physiological stress indcators and improving well-being and mental health. Unpublished doctoral dissertation, University of Utah, Salt Lake City. Retrieved from ProQuest Dissertations and Theses (www.proquest.com).

Lopes, P. N., Salovey, P., Coté, S., \& Beers, M. (2005). Emotion regulation abilities and the quality of social interaction. Emotion, 5(1), 113-118.

Lösel, F., \& Beelmann, A. (2003). Effects of child skills training in preventing antisocial behavior: A systematic review of randomized evaluations. Annals of the American Academy of Political and Social Science, 587(1), 84-109.

Lynch, S., Gander, M., Kohls, N., Kudielka, B., \& Walach, H. (2011). Mindfulness-based coping with university life: A non-randomized wait-list controlled pilot evaluation. Stress and Health, 27, 365-375.

Lyons, M. D., \& Lufkin, B. (1967). Evaluation of tension control courses for college women. Research Quarterly of the American Association for Health, Physical Education, and Recreation, 38(4), 663-670.

MacLeod, A. K., Coates, E., \& Hetherton, J. (2008). Increasing well-being through teaching goal-setting and planning skills: Results of a brief intervention. Journal of Happiness Studies, 9, 185-196.

Markman, H., Stanley, S., \& Blumberg, S. L. (2001). Fighting for your marriage: Positive steps for preventing divorce and preserving a lasting love. San Francisco: Jossey-Bass.

Mattanah, J. F., Ayers, J. F., Brand, B. L., Brooks, L. J., Quimby, J. L., \& McNary, S. W. (2010). A social support intervention to ease the college transition: Exploring main effects and moderators. Journal of College Student Development, 51(1), 93-108.

Mayer, J. D., Salovey, P., \& Caruso, D. R. (2004). Emotional intelligence: Theory, findings, and implications. Psychological Inquiry, 15(3), 197- 215.

McDonald, T. W., Pritchard, M. E., \& Landrum, R. E. (2006). Facilitating preventative mental health interventions for college students: Institutional and individual strategies. In M. V. Landow (Ed.), Stress and mental health of college students (pp. 225-241). New York: Nova Science.

Meichenbaum, D. (1985). Stress inoculation training. New York: Pergamon Press.

Moss, S. B. (2003). The effects of cognitive behavior therapy, meditation, and yoga on selfratings of stress and psychological functioning in college students. Unpublished doctoral dissertation, University of Southern Mississippi, Hattiesburg, MS. Retrieved from ProQuest Dissertations and Theses (www.proquest.com).

Oman, D., Shapiro, S. L., Thoresen, C. E., Plante, T. G., \& Flinders, T. (2008). Meditation lowers stress and supports forgiveness among college students: A randomized controlled trial. Journal of American College Health, 56(5), 569-578. 


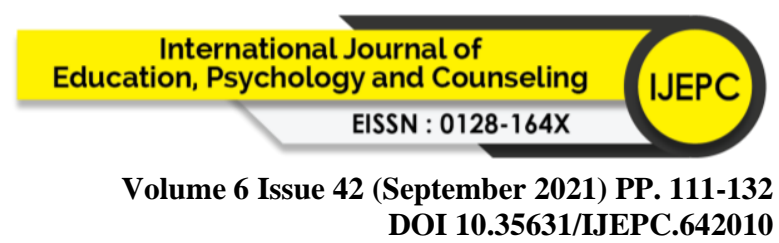

Palmer, A., \& Roger, S. (2009). Mindfulness, stress, and coping among university students. Canadian Journal of Counseling, 43(3), 198-212.

Parker, J. D. A., Duffy, M. J., Wood, L. M., Bond, B. J., \& Hogan, M. J. (2005). Academic achievement and emotional intelligence: Predicting the successful transition from high school to university. Journal of the First-Year Experience, 17(1), 67-78.

Pritchard, M. E., \& Wilson, G. S. (2003). Using emotional and social factors to predict student success. Journal of College Student Development, 44(1), 18-28.

Ramos-Sanchez, L., \& Nichols, L. (2007). Selfefficacy of first-generation and nonfirstgeneration college students: The relationship with academic performance and college adjustment. Journal of College Counseling, 10(1), 6-18.

Ratanasiripong, P., Ratanasiripong, N., \& Kathalae, D. (2012). Biofeedback intervention for stress and anxiety among nursing students: A randomized controlled trial. ISRN Nursing, 2012, Article 827972.

Robbins, S. B., Lauver, K., Le, H., Davis, D., Langley, R., \& Carlstrom, A. (2004). Do psychosocial and study skill factors predict college outcomes?: A meta-analysis. Psychological Bulletin, 130(2), 261-288.

Rosenzweig, S., Reibel, D. K., Greeson, J. M., Brainard, G. C., \& Hojat, M. (2003). Mindfulnessbased stress reduction lowers psychological distress in medical students. Teaching and Learning in Medicine, 15(2), 88-92.

Seal, C. R., Naumann, S. E., Scott, A. N., \& RoyceDavies, J. (2010). Social emotional development: A new model of student learning in higher education. Research in Higher Education Journal, 10, 1-13.

Sears, S. R., \& Kraus, S. (2009). I think therefore I om: Cognitive distortions and coping style as mediators for the effects of mindfulness meditation on anxiety, positive and negative affect, and hope. Journal of Clinical Psychology, 65(6), 561-573.

Shapiro, S. L., Brown, K. W., \& Biegel, G. M. (2007). Teaching self-care to caregivers: Effects of mindfulness-based stress reduction on the mental health of therapists in training. Training and Education in Professional Psychology, 1(2), 105-115.

Shapiro, S. L., Oman, D., Thoresen, C. E., Plante, T. G., \& Flinders, T. (2008). Cultivating mindfulness: Effects on well-being. Journal of Clinical Psychology, 64(7), 840-862.

Shapiro, S. L., Schwartz, G. E., \& Bonner, G. (1998). Effects of mindfulness-based stress reduction on medical and premedical students. Journal of Behavioral Medicine, 21, 581-599.

Smith, J. C. (1975). Meditation as psychotherapy: A review of the literature. Psychological Bulletin, 82(4), 558-564.

Stallman, H. M. (2010). Psychological distress in university students: A comparison with general population data. Australian Psychologist, 45(4), 249-257.

Stewart-Brown, S., Evans, J., Patterson, J., Petersib, S., Doll, H., Balding, J., et al. (2000). The health of students in institutes of higher education: An important and neglected public health problem? Journal of Public Health Medicine, 22(4), 492- 499.

Tao, S., Dong, Q., Pratt, M. W., Hunsberger, B., \& Pancer, S. M. (2000). Social support: Relations to coping and adjustment during the transition to university in the People's Republic of China. Journal of Adolescent Research, 15(1), 123-144.

Turner, J. T. (1991). The effect of a biofeedback and stress management course on college student anxiety and academic performance. Unpublished doctoral dissertation, University of Northern Colorado, Greeley. 


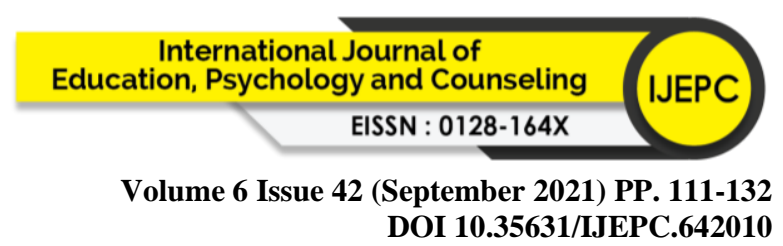

Waldo, M. (1982, August). Relationship skills workshops in university residence halls: A preventive intervention. Paper presented at the annual convention of the American Psychological Association, Washington, DC.

Walker, R., \& Frazier, A. (1993). The effect of a stress management educational program on the knowledge, attitude, behavior, and stress level of college students. Wellness Perspectives, 10(1), 52-60.

Winterdyk, J., Ray, H., Lafave, L., Flessati, S., Huston, M., Danelesko, E., et al. (2008). The evaluation of four mind/body intervention strategies to reduce perceived stress among college students. College Quarterly, 11(1), 1-10.

Winzelberg, A. J., \& Luskin, F. M. (1999). The effect of a meditation training in stress levels in secondary school teachers. Stress Medicine, 15(2), 69-77.

Wolaver, A. M. (2002). Effects of heavy drinking in college on study effort, grade point average, and major choice. Contemporary Economic Policy, 20(4), 415-428.

Yager, Z., \& O'Dea, J. A. (2008). Prevention programs for body image and eating disorders on university campuses: A review of large, controlled interventions. Health Promotion International, 23(2), 173-189.

Zins, J. E., Bloodworth, M. R., Weissberg, R. P., \& Walberg, H. J. (2004). The scientific base linking social and emotional learning to school success. In J. E. Zins, R. P. Weissberg, M. C. Wang, \& H. J. Walberg (Eds.), Building academic success on social and emotional learning: What does the research say (pp. 3-39). New York: Teachers College Press.

Zins, J. E., \& Elias, M. J. (2006). Social and emotional learning. In G. G. Bear, K. M. Minke, \& National Association of School Psychologists (Eds.), Children's needs III: Development, prevention, and intervention (pp. 1-14). Bethesda, MD: National Association of School Psychologists.

Zins, J. E., Weissberg, R. P., Wang, M. C., \& Walberg, H. J. (2004). Building academic success on social and emotional learning: What does the research say? New York: Teachers College Press.

Zuroff, D. C., \& Schwarz, J. C. (1978). Effects of transcendental meditation and muscle relaxation on trait anxiety, maladjustment, locus of control, and drug use. Journal of Consulting and Clinical Psychology, 46, 264-271. 